\title{
Efeito de diferentes níveis de sombreamento no crescimento inicial de Unha de gato (Uncaria tomentosa Willd.)
}

\author{
LUNZ, A.M.P.1*; SILVA JÚNIOR, E.C.2; DE OLIVEIRA, L.C. ${ }^{*}$ \\ ${ }^{1}$ Embrapa Acre, Rodovia BR-364, Km 14. CEP 69908-970. Rio Branco, AC - Brasil, Email: aureny@cpafac. \\ embrapa.br; '2Universidade Federal do Acre. BR-364, Km 04 - Distrito Industrial. CEP: 69915-900, Rio Branco, \\ AC - Brasil.
}

\begin{abstract}
RESUMO: A unha de gato (Uncaria tomentosa Willd.) é uma das muitas espécies de plantas com propriedades medicinais utilizadas pelas comunidades nativas da Amazônia para o tratamento de diversas doenças. Suas inúmeras propriedades medicinais têm provocado nos últimos anos o aumento da demanda por essa planta, a qual vem sendo explorada de forma indiscriminada e predatória. O conhecimento agronômico disponível atualmente sobre essa espécie é escasso; dessa forma, o objetivo do presente trabalho foi avaliar o efeito de diferentes níveis de sombreamento no crescimento inicial da Unha de gato. O experimento foi realizado no viveiro da área experimental da Embrapa Acre, no município de Rio Branco, AC, no período de maio de 2009 a junho de 2010. Foram avaliados quatro tratamentos, constituídos por diferentes níveis de sombreamento $(30 \%, 50 \%$ e $70 \%)$ e pleno Sol, obtidos com tela sombrite preta, com as referidas capacidades de retenção da radiação solar. O delineamento experimental utilizado foi o de blocos casualizados, com oito repetições, contendo duas plantas por parcela. As variáveis analisadas foram: altura da parte aérea, diâmetro do colo, biomassa do sistema radicular, biomassa aérea, biomassa total e partição de biomassa. O crescimento da Unha de gato foi modificado pela intensidade de sombreamento. A altura das plantas e a massa seca das raízes aumentaram linearmente com a intensidade de sombreamento. Sombreamentos entre 55 a $60 \%$ proporcionaram melhores crescimentos para as variáveis: diâmetro do coleto, massa seca da parte aérea e massa seca total. Não houve variação na distribuição de massa seca entre a parte aérea e o sistema radicular das plantas em função do sombreamento. Verificou-se que o sombreamento na faixa de 55 a $60 \%$ é o mais indicado para o seu crescimento inicial.
\end{abstract}

Palavras-chave: Amazônia, planta medicinal, radiação solar

\begin{abstract}
Effect of different levels of shading on the growth of cat's claw (Uncaria tomentosa Willd.). Cat's claw (Uncaria tomentosa Willd.). Is one among many plant species with medicinal properties, used by the native communities of the Amazon to treat several diseases. Its numerous medicinal properties have caused in recent years an increase in demand and the plant has been exploited in an indiscriminate and predatory way. The agronomic knowledge available on this species is scarce, so the purpose of this study was to evaluate the effect of different levels of shading on early growth of Uncaria tomentosa. The experiment was established in the nursery of Embrapa Acre, in the city of Rio Branco, state of Acre, Brazil, from May 2009 to June 2010. We tested four levels of shading (30\%, 50\% and $70 \%)$ and full sunlight, obtained with black shade screens. The experimental design was a randomized block, with eight replications and two plants per plot. The variables analyzed were: height of shoots, stem diameter, root dry matter, aerial dry matter, total dry matter and dry matter partitioning. The growth of Uncaria tomentosa was modified by the intensity of shading. Plant height and dry weight of the roots increased linearly with the intensity of shading. Shading around 55 to $60 \%$ provided better growth for the stem diameter, shoot dry matter and total dry matter. There was no change in the distribution of the dry matter between the shoot and root systems of the plants. For the species Uncaria tomentosa, we found that shading in the range of 55 to $60 \%$ is the most indicated for its early growth.
\end{abstract}

Keywords: Amazon, medicinal plant, solar radiation. 


\section{INTRODUÇÃO}

A Unha de gato (Uncaria tomentosa Willd.) é uma liana da família Rubiaceae que ocorre em países da América Central e do Sul, incluindo amplas áreas da Amazônia brasileira (Reinhard, 1999; Falkiewicz \& Lukasiak, 2001). É uma, dentre as muitas espécies de plantas com propriedades medicinais, utilizadas por comunidades nativas da Amazônia para o tratamento de diversas doenças (Keplinger et al. 1999; Williams, 2001).

Segundo estudos químicos, biológicos e farmacológicos essa espécie possui efeitos imunoestimulantes, antiflamatórios, antiviral, inibidores do crescimento de células cancerígenas, entre outros (Williams, 2001; Sandoval et al., 2002; Souza \& Cimerman, 2010). Tais propriedades têm levado seu amplo uso no tratamento de AIDS, de câncer e de outras doenças que afetam o sistema imunológico (Williams, 2001).

Estudos fitoquímicos da casca, raízes e folhas da Unha de gato demostraram a presença de diversos tipos de alcalóides, com destaque para o grupo dos oxindólicos (Torrejon, 1997; Sandoval et al. 2002; Souza \& Cimerman, 2010). O crescente interesse de laboratórios internacionais pelo produto resultou no registro de seus extratos, os quais foram amplamente comercializados para uso oral (C-MED-100® e Krallendom $®$ ) como um poderoso estimulante do sistema imunológico (Souza \& Cimerman, 2010). Durante a década de 90, mais de 50 formas de suplementos dietéticos à base de Unha de gato foram comercializados no mercado farmacêutico nos Estados Unidos (Keplinger et al., 1999).

As propriedades terapêuticas, a complexidade e a diversidade estrutural de seus componentes e seus mecanismos de ação, assim como seus aspectos ecológicos e econômicos têm despertado nos últimos trinta anos o interesse de médicos, farmacólogos, químicos, botânicos, agrônomos e economistas (Pereira \& Lopes, 2006).

A exploração da Unha de gato é feita por populações nativas, predominantemente no Peru e mais recentemente no Estado do Acre (Zevallos et al., 2000; Miranda et al., 2001; Miranda et al., 2003). Suas inúmeras propriedades medicinais têm provocado, nos últimos anos, o aumento na demanda por essa planta, que vem sendo explorada de forma indiscriminada e predatória (Jones, 1995), sendo classificada na categoria $\mathrm{VU}$, que representa perigo em médio prazo (Pollito \& Tomazello Filho, 2010). Tal fato pode provocar a redução de sua variabilidade genética e até mesmo sua extinção, evidenciando a necessidade de regularização e fiscalização das florestas nativas, com seu manejo e implantação de novas plantações (Zevallos et al., 2000; Miranda et al., 2001; Pereira \& Lopes, 2006;
Pollito \& Tomazello Filho, 2010).

O conhecimento agronômico disponível atualmente sobre a espécie é escasso em muitos aspectos importantes para o desenvolvimento de técnicas agronômicas visando o seu cultivo racional (Bendezu, 1995). Dessa forma, estudos que envolvam ecologia, ecofisiologia, biologia reprodutiva, propagação, melhoramento genético, manejo e silvicultura da Unha de gato tornam-se importantes para o desenvolvimento da tecnologia de cultivo.

Entre os diversos componentes do ambiente, a radiação solar é primordial para o crescimento das plantas, não só por fornecer energia para a fotossíntese, mas também por fornecer sinais que regulam seu desenvolvimento através de receptores de luz, sensíveis a diferentes intensidades e qualidade espectral (Taiz \& Zeiger, 2004). Portanto, modificações nos níveis de luminosidade, ao qual uma espécie está adaptada, podem condicionar diferentes respostas fisiológicas em suas características bioquímicas, anatômicas e de crescimento (Atroch et al., 2001; Carvalho, N.O.S. et al., 2006).

A eficiência do crescimento pode estar relacionada à habilidade de adaptação das plantas às condições de intensidade luminosa do ambiente (Larcher, 2000). Assim como, a disponibilidade de radiação também pode ser um fator que altere a produção de compostos secundários nas plantas (Scheffer, 2002; Nina \& Lerdau, 2003; Gobbo-Neto \& Lopes, 2007). Conforme Dousseau et al. (2007), o sucesso na adaptação de uma espécie em diferentes condições de radiação está relacionado com a eficácia e rapidez com que os padrões de alocação de biomassa e comportamento fisiológico são ajustados.

O objetivo deste trabalho foi avaliar o efeito de diferentes níveis de sombreamento no crescimento inicial da Unha de gato.

\section{MATERIAL E MÉTODOS}

O experimento foi conduzido no viveiro da área experimental da Embrapa Acre, no município de Rio Branco - AC, no período de maio de 2009 a junho de 2010. Utilizou-se sementes de Uncaria tomentosa (Willd. ex Roem. \& Schult.) DC., oriundas de plantas de 5 anos de idade, existentes na coleção de plantas medicinais da Embrapa Acre.

A semeadura foi realizada em copos de plástico descartável com substrato de areia e cobertura de casca de arroz carbonizada; após a germinação, as plântulas foram transplantadas para vasos de Polipropileno com substrato de terra de solo + adubo orgânico (esterco de gado 
curtido) + areia lavada, na proporção de 2:1:1. As mudas ficaram no viveiro com disponibilidade de radiação solar de $50 \%$ durante o período de aproximadamente três meses, quando então foram aplicados os tratamentos constituídos por quatro níveis de sombreamento: pleno Sol, 30\%, 50\% e $70 \%$. O nível de sombreamento foi obtido com tela sombrite preta, com as referidas capacidades de retenção da radiação solar. Durante a condução do experimento foram efetuadas regas diárias a fim de manter a capacidade de campo do substrato.

O delineamento experimental foi o de blocos casualizados, com 4 tratamentos e 8 repetições, com 2 plantas por parcela. Decorridos 13 meses após a semeadura efetuou-se a avaliação do experimento. As variáveis analisadas foram: altura da parte aérea (medida do colo da muda até a gema apical), diâmetro do colo (medida no colo da planta), biomassa radicular (depois de seccionado o caule na altura do colo, cuidadosa lavagem das raízes e posterior secagem em estufa), biomassa aérea (secagem em estufa e pesagem) e biomassa total. Para determinação da massa seca, as diferentes partes da planta (raiz, caule, ramos e folhas) foram separadas e acondicionadas em sacos de papel para secagem em estufa com ventilação forçada, a $70^{\circ} \mathrm{C}$, até peso constante, aproximadamente 72 horas, sendo posteriormente pesadas.

Realizou-se inicialmente a análise exploratória dos dados para verificação da normalidade e homogeneidade de variâncias dos mesmos. As variáveis que não apresentaram normalidade sofreram transformação de dados para, em seguida, proceder-se a análise de variância pelo programa estatístico SAS - Statistical Analysis System, versão 9.1 (SAS, 2003). Quando significativo, efetuou-se a análise de regressão, verificando-se a melhor equação a ser ajustada para cada variável.

\section{RESULTADOS E DISCUSSÃO}

Todas as variáveis avaliadas, exceto a razão de massa seca, foram afetadas significativamente $(p<0,05)$ pelo nível de sombreamento incidente nas plantas de Uncaria tomentosa.

Para a variável diâmetro do colo obtevese uma função polinomial de $3^{\circ}$ grau (Figura 1). Observou-se o acréscimo de diâmetro a medida que se aumentou o sombreamento verificando-se o nível ótimo, estimado pela regressão, na condição de aproximadamente $60 \%$ de sombra. A partir desse ponto, a baixa disponibilidade de radiação solar tornou-se limitante ao aumento do diâmetro do caule.

Em estudo realizado por Almeida et al. (2005), avaliando os efeitos de diferentes condições de sombreamento em plantas jovens de espécies florestais, verificou-se a redução no diâmetro do caule da Acacia mangium Willd. à medida que se aumentou o sombreamento, enquanto que na espécie Senna macranthera (Collad.) Irwin et Barn. os maiores diâmetros ocorreram sob condições de sombreamento.

O crescimento em diâmetro apresenta uma relação direta com a fotossíntese líquida (Larcher, 2000). Esse fato pode ser observado no presente trabalho quanto aos resultados de biomassa total que apresentou comportamento similar à variável diâmetro do colo.

O sombreamento favoreceu o crescimento em altura das plantas de Uncaria tomentosa. Houve acréscimo linear dessa variável com o aumento do sombreamento (Figura 2). Esse maior

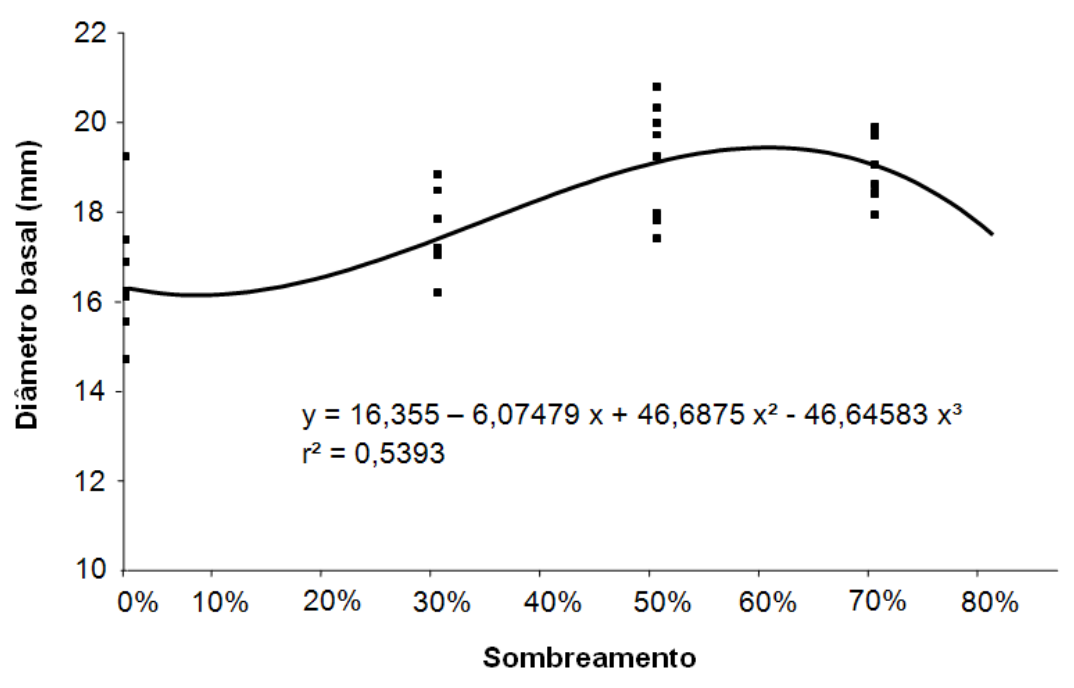

FIGURA 1. Diâmetro do colo de Uncaria tomentosa aos 13 meses após semeadura, em função do sombreamento. 
crescimento em altura nas plantas com redução da disponibilidade de radiação solar é conhecido como estiolamento, onde estas se alongam em busca de luminosidade. Resultados semelhantes foram observados em outras espécies, tais como: Gallesia integrifolia (Spreng) Harmes (Demuner et al., 2004), Tanacetum parthenium (L.) Schultz.-Bip. (Carvalho LM et al., 2006), Hymanaea parvifolia Huber. (Silva et al., 2007) e Tapirira guianensis Alb. (Dousseau et al., 2007).

De acordo com Taiz \& Zeiger (2004) as plantas alongam o caule em resposta ao sombreamento como forma de evitar a baixa irradiância de luz solar. Afirmam que o sombreamento simulado de um dossel com seu alto nível de luz vermelho-distante induz as plantas de sol a alocarem a maior parte de seus recursos para aumentar a altura. Os autores citam que plantas de sombra mostram pouca ou nenhuma redução em sua taxa de alongamento caulinar à medida que são expostas a maiores valores da razão vermelho/vermelho distante.

A massa seca da raiz foi diretamente proporcional ao sombreamento incidente nas plantas (Figura 3), ou seja, ela foi maior nas plantas conduzidas sob baixa disponibilidade de radiação solar. De modo oposto, Freitas et al. (2012) verificaram aumento da produção de biomassa radicular em Sclerolobium paniculatum Vogel, com a elevação da intensidade luminosa; enquanto Dousseau et al. (2007) e Dutra et al. (2012) não detectaram efeito do sombreamento para essa variável em mudas de Tapirira guianensis Alb. e Copaifera langsdorffii Desf., respectivamente.

Pode-se observar que a variável biomassa da parte aérea da espécie apresentou comportamento de função polinomial de $3^{\circ}$ grau

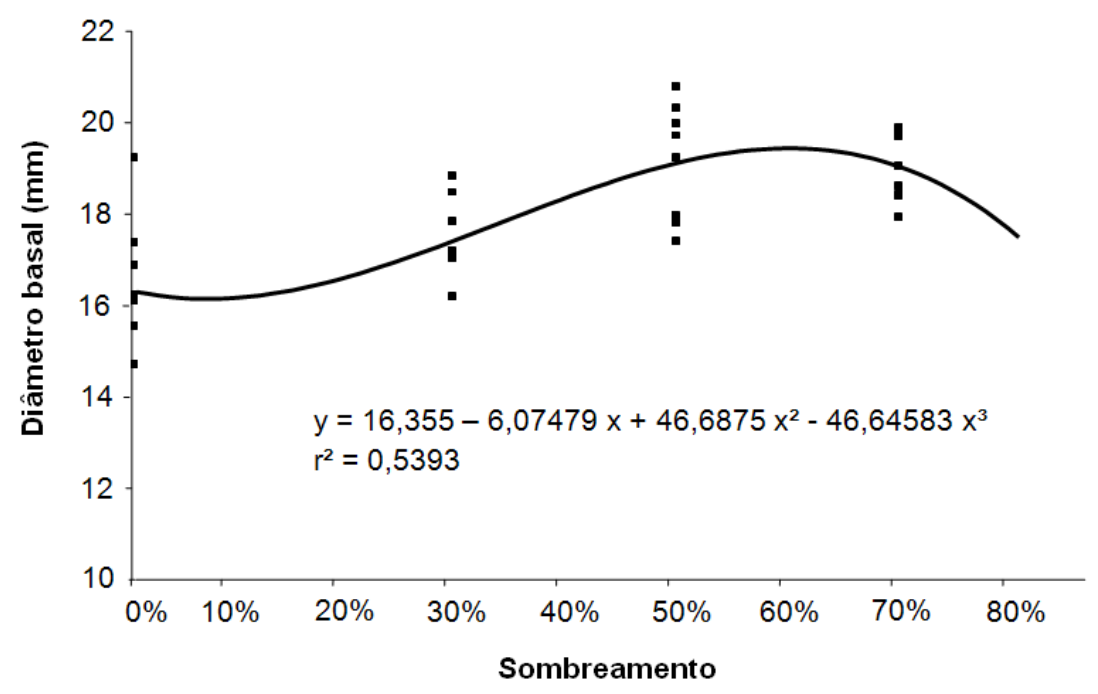

FIGURA 2. Altura de Uncaria tomentosa aos 13 meses após semeadura, em função do sombreamento.

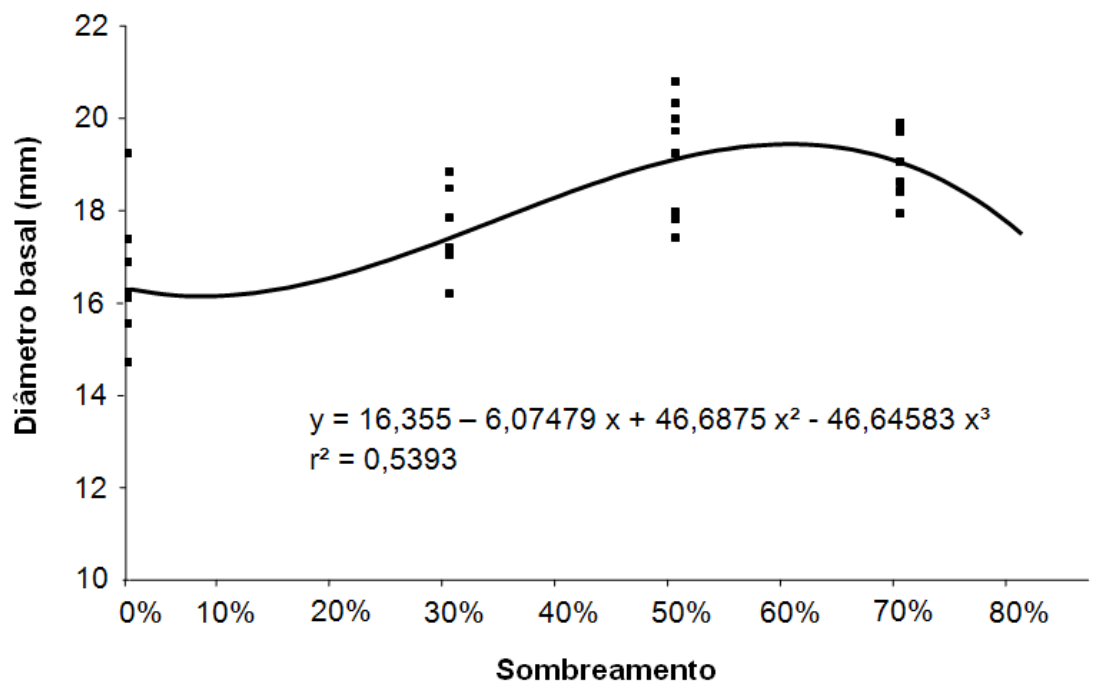

FIGURA 3. Massa seca da raiz de Uncaria tomentosa aos 13 meses após semeadura, em função do sombreamento. 
(Figura 4) apresentando os maiores valores, estimados pela regressão, quando submetidas a aproximadamente $57 \%$ de sombreamento. Os valores de biomassa aérea foram reduzidos sob alta e baixa disponibilidade de radiação solar.

Para os dados logaritmizados, observa-se o aumento da massa seca total com a elevação da intensidade de sombreamento, estimado pela regressão, até aproximadamente $57 \%$. A partir desse nível, a sombra passou a ser limitante ao acúmulo de biomassa total (Figura 5). Mota et al. (2012) observaram maior produção de massa seca total em mudas de Dipteryx alata Vog. quando submetidas a sombreamentos de 50 e $70 \%$. Para a biomassa total de mudas de Tapirira guianensis Alb. e Copaifera langsdorffii Desf. Dousseau et al. (2007) e Dutra et al. (2012) respectivamente, não detectaram efeito do sombreamento, enquanto Freitas et al. (2012) verificaram elevação da produção de massa seca total em Sclerolobium paniculatum Vogel, com o aumento da irradiancia disponível.

Apesar de ser considerada uma espécie heliófita, segundo Bendezu (1999), a Uncaria tomentosa pode ser tolerante a sombra, mas, com o passar do tempo, esse caráter heliófito se acentua. Nas condições do experimento essa espécie demonstrou ser uma planta que não apenas possui a capacidade de tolerar a sombra, mas nitidamente é favorecida por níveis de sombreamentos intermediários (55 a 60\%), pelo menos durante a sua fase inicial de crescimento; inclusive não sendo capaz de crescer de maneira satisfatória nas condições de pleno sol ou sombreamento intenso, conforme a baixa produção de biomassa observada nessas condições (Figura 5).
Não houve efeito significativo do sombreamento na razão de massa seca (parte aérea/sistema radicular), que foi de 3,12 , ou seja, a parte aérea representou aproximadamente $75 \%$ da massa seca total de plantas de Uncaria tomentosa, independente do nível de sombreamento. Tais resultados indicam que em todos os níveis de disponibilidade de radiação solar as plantas investiram maior quantidade de fotoassimilados para a parte aérea, do que para as raízes.

Estudos com mudas de algumas espécies, tais como, Hymenaea parvifolia Huber (Silva et al., 2007), Caesalpinia ferrea Mart. ex Tul. (Lima et al., 2008), Sclerolobium paniculatum Vogel (Freitas et al., 2012) apresentaram redução da razão de massa seca com a elevação da disponibilidade de radiação solar. De acordo com Poorter et al. (2012) as plantas, em geral, alocarão relativamente mais biomassa para a parte aérea se o fator limitante for acima do solo. Dessa forma, plantas cultivadas em condições de pouca disponibilidade de radiação solar apresentarão aumento de alocação de biomassa para a parte aérea. Contudo, tais características não foram observadas para a Uncaria tomentosa nesse experimento, assim como para a espécie Copaifera langsdorffii Desf. (Dutra et al., 2012), que apresentaram maior alocação de massa seca para a parte aérea da planta, independente do nível de sombreamento a que foram submetidas.

O nível de sombreamento não afetou a distribuição de massa seca entre folhas, ramos, caule e raiz em plantas de Uncaria tomentosa. Houve pequena alocação diferenciada de recursos, independente da disponibilidade de radiação solar, para as diferentes partes da planta. A proporção de

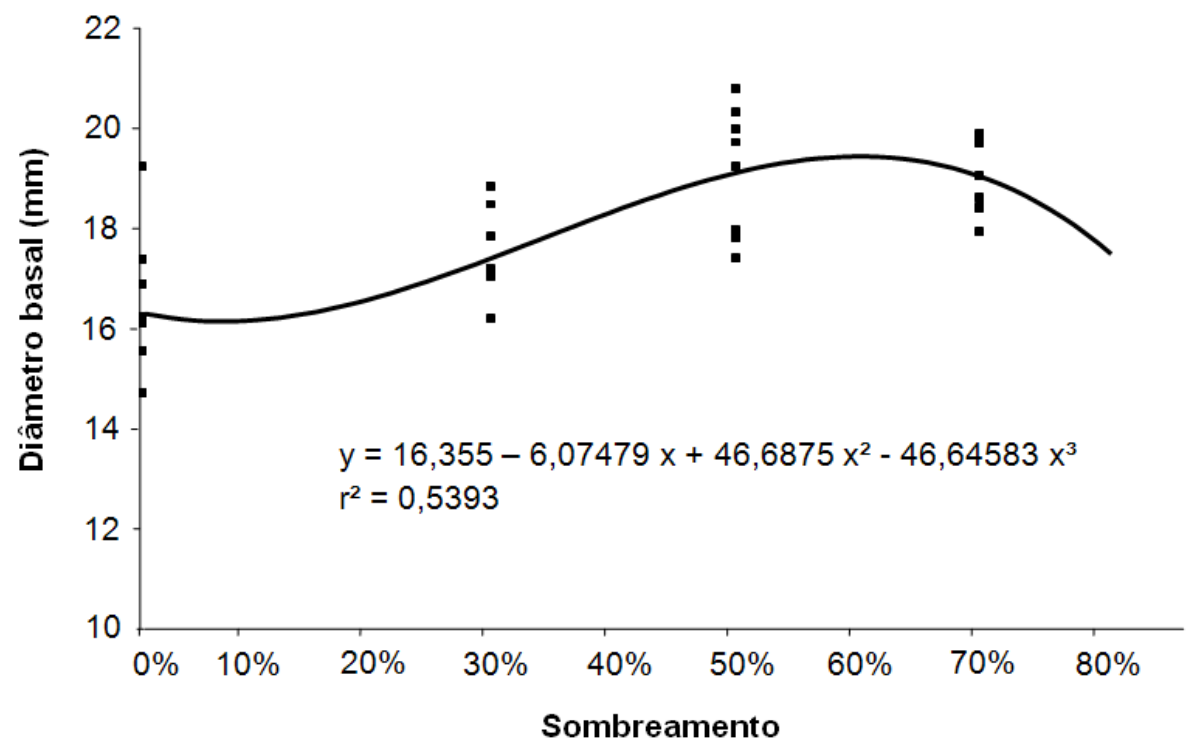

FIGURA 4. Massa seca da parte aérea de Uncaria tomentosa aos 13 meses após semeadura, em função do sombreamento. 


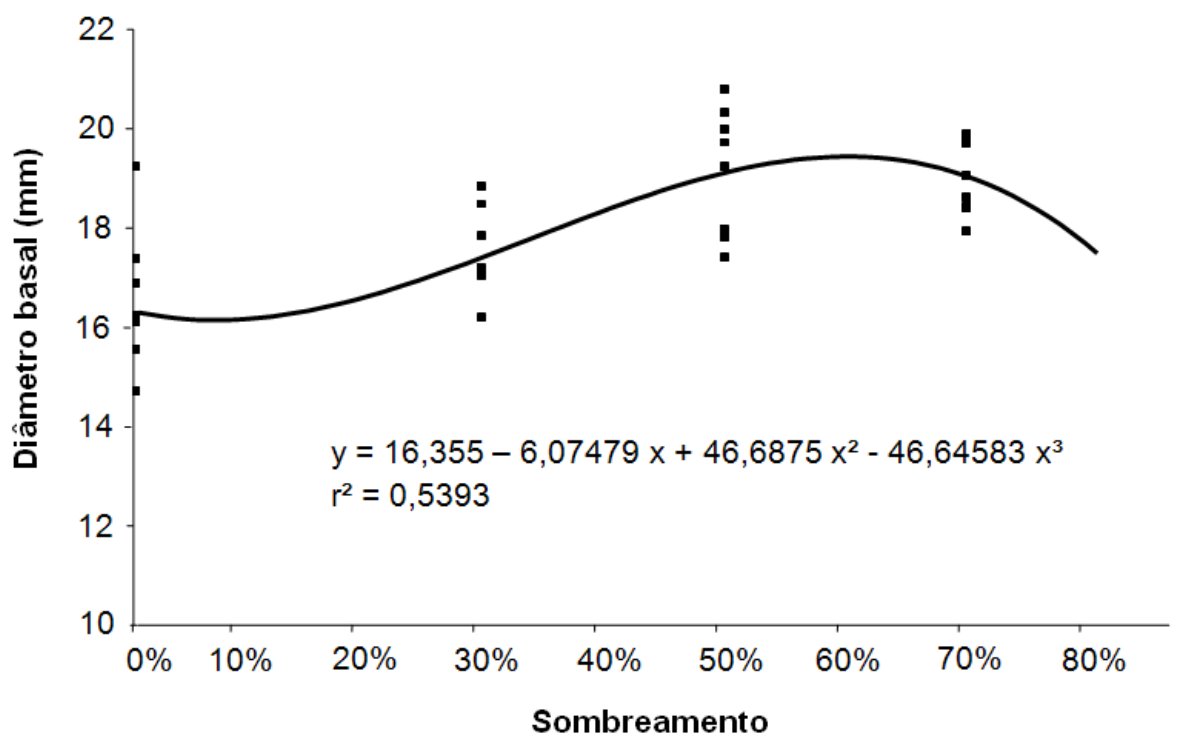

FIGURA 5. Massa seca total de Uncaria tomentosa 13 meses após semeadura, em função do sombreamento.

massa seca foi de aproximadamente $31,26,23$ e $20 \%$ para o caule, as raízes, os ramos e as folhas, respectivamente.

No presente estudo não foi avaliado o efeito da disponibilidade de radiação solar sobre a produção de compostos secundários dessa espécie, a qual pode ser influenciada tanto pela quantidade como pela qualidade de luz e, inclusive, resultar em comportamento diferenciado em função da espécie, bem como do tipo de compostos produzidos (Scheffer, 2002). Pesquisas realizadas com outras espécies têm apresentado resultados variados. Carvalho, L.M. et al. (2006) não verificaram efeito significativo do sombreamento sobre os teores de partenolídeos em plantas de Tanacetum parthenium
(L.) Schultz.-Bip.; em contrapartida, Cai et al., (2009) observaram aumento na concentração do alcalóide reserpina para a espécie Rauvofia vomitoria Afzel; enquanto que em Rauvofia verticillatae (Lour.) Baill a elevação da irradiância reduziu a concentração de reserpina.

Diante dos resultados obtidos no presente trabalho conclui-se que houve efeito positivo do sombreamento no crescimento inicial de Uncaria tomentosa, sendo que o nível ótimo de sombreamento para o crescimento inicial dessa espécie está entre 55 a $60 \%$. Todavia, sugere-se que novas pesquisas sejam efetuadas a fim de avaliar a influência da disponibilidade de radiação solar no teor de alcalóides dessa espécie.
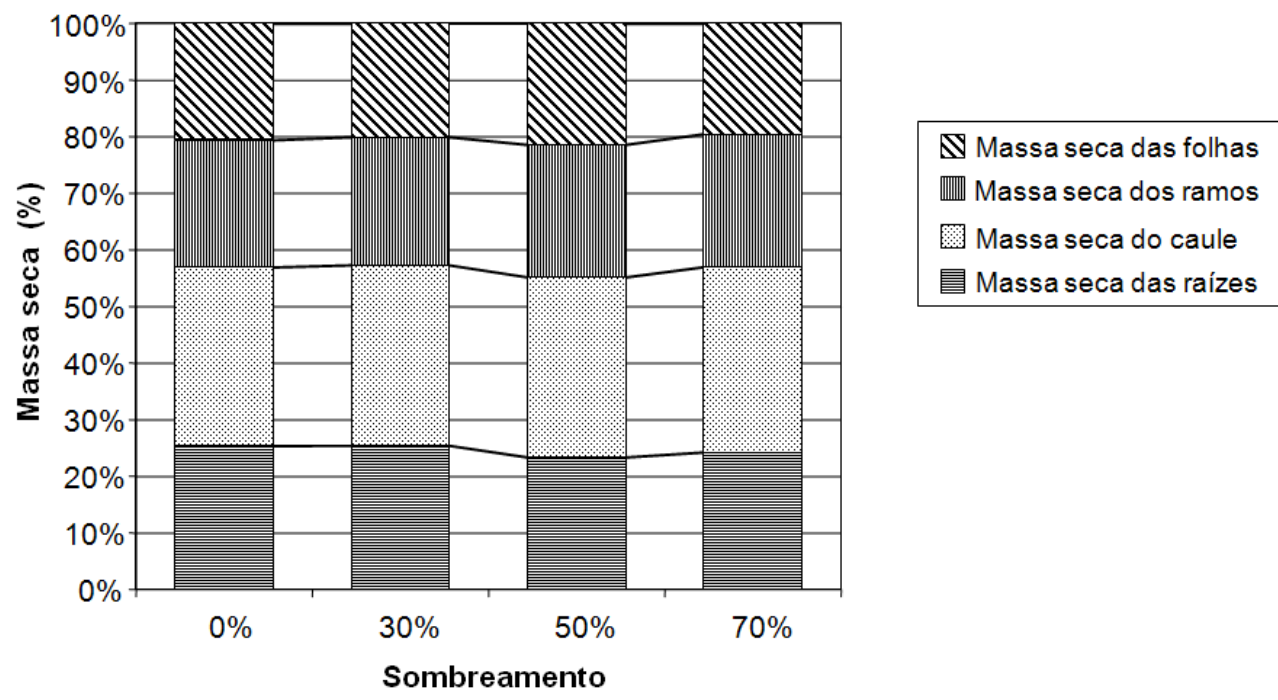

FIGURA 6. Partição de massa seca entre a parte aérea e o sistema radicular e entre as diferentes partes da planta de Uncaria tomentosa aos 13 meses após semeadura, em função do sombreamento. 


\section{REFERÊNCIA}

ALMEIDA, S.M.Z. et al. Alterações morfológicas e alocação de biomassa em plantas jovens de espécies florestais sob diferentes condições de sombreamento. Ciência Rural. v.35, n.1, p.62-68, 2005.

ATROCH, E.M.A.C. et al. Crescimento, teor de clorofilas, distribuição de biomassa e características anatômicas de plantas jovens de Bauhinia forticata LINK submetidas a diferentes condições de sombreamento. Ciência e Agrotecnologia. v.25, n.4, p.853-862, 2001.

BENDEZU, Y.F. Propagacion por semilla de la uña de gato (Uncaria tomentosa). Lima: INIA, 1995. 32p. (Boletin Técnico, 5).

BENDEZU, Y.F. Estudio experimental de crescimiento de uña de gato em plantaciones artificiales. Lima: INIA, 1999. 20p.

CAI, Z.Q. et al. Growth, photosynthesis and root reserpine concentrations of two Rauvolfia species in response to a light gradient. Industrial Crops and Products. v.30, 220-226, 2009.

CARVALHO L.M. et al. Crescimento e metabolismo em artemísia em função do nível de irradiância. Horticultura Brasileira. v.24, n.3, 289-294, 2006.

CARVALHO, N.O.S. et al. Crescimento inicial de plantas de licuri (Syagrus coronata (MART.) BECC.) em diferentes níveis de luminosidade. Revista Árvore. v.30, n.3, p.351-357, 2006.

DEMUNER, G.V.; HEBLING, A.S.; DAGUSTINHO, M.D. Efeito do sombreamento no crescimento inicial de Gallesia integrifólia (Spreng.) Harms. Boletim do Museu de Biologia Mello Leitão. v.17, p.45-55, 2004.

DOUSSEAU, S. et al. Influência de diferentes condições de sombreamento sobre o crescimento de Tapirira guianensis Alb. Revista Brasileira de Biociências. v.5, n.2, p.477-479, 2007.

FALKIEWICZ, B.; LUKASIAK, J. Vilcacora [Uncaria tomentosa (Willd.) DC. and Uncaria guianensis (Aublet) Gmell.]: a review of published scientific literature. Case Reports and Clinical Practice Review. v.2, n.4, p.305-316, 2001.

FREITAS, G.A. de. Influência do sombreamento na qualidade de mudas de Sclerolobium paniculatum Vogel para recuperação de área degradada. Journal of Biotechnology and Biodiversity. v.3, n.3, p.5-12, 2012.

GOBBO-NETO, L.; LOPES, N.P. Plantas medicinais: fatores de influência no conteúdo de metabólitos secundários. Química Nova. v.30, n.2, p.374-381, 2007.

JONES, K. Cat's claw: Healing vine of Peru. Seattle: Sylvan Press, 1995. 152p.

KEPLINGER, K. et al. Uncaria tomentosa (Willd.) DC - Ethnomedicinal use and new pharmacological, toxicological and botanical results. Journal of Ethnopharmacology. v.64, n. 1, p.23-34, 1999.

LARCHER, W. Ecofisiologia vegetal. Tradução de C.H.B.A. Prado. São Carlos: Rima, 2000. 532p.

LIMA, J.D. et al. Efeitos da luminosidade no crescimento de mudas de Caesalpinia ferrea Mart. ex Tul. (Leguminosae, Caesalpinoideae). Acta Amazônica. v.38, n.1, p.5-10, 2008.

MIRANDA, E.M.; SOUSA, J.A.; PEREIRA, R. de C.A. Subsídios técnicos para o manejo sustentável da unha de gato (Uncaria spp.) no Vale do Rio Juruá, AC. Rio Branco: Embrapa Acre, 2001. 21 p. (Embrapa Acre. Documentos, 68).

MIRANDA, E.M.; SOUSA, J.A.; PEREIRA, R.C.A. Caracterização e avaliação de populações nativas de unha de gato [Uncaria tomentosa (Willd.) DC. e U. guianensis (Aubl.) Gmel.] no vale do rio Juruá-AC. Revista Brasileira de Plantas Medicinais. v.5, n.2, p.41-46, 2003.

MOTA, L.H. de S.; SCALON, S. de P.Q.; HEINZ, R. Sombreamento na emergência de plântulas e no crescimento inicial de Dipteryx alata Vog. Ciência Florestal. v.22, n.3, p.423-431, 2012.

NINA, T.; LERDAU, M. The evolution of function in plant secondary metabolites. International Journal of Plant Sciences. v.164, n.S3, p.93-102, 2003.

PEREIRA, R.C.A.; LOPES, J.V.M. Aspectos Botânicos, Etnobotânicos, Agronômicos e Fitoquímicos de Unha de Gato. Fortaleza: EMBRAPA Agroindustria Tropical, 2006. 34p.

POLLITO, P.A.Z.; TOMAZELLO FILHO, M. Levantamento e caracterização de duas espécies do gênero Uncaria schreb. (RUBIACEAE) correntes no estado do Acre, Brasil. Ecología Aplicada. v.9, n.1, p.19-30, p.1930, 2010.

REINHARD, K.H. Uncaria tomentosa (Willd.) D.C: Cat's Claw, Uña de Gato, or Savéntaro. The Journal of Alternative and Complementary Medicine. v.5, n.2, p.143-151, 1999.

POORTER, H. et al. Biomass allocation to leaves, stems and roots: meta-analyses of interspecific variation and environmental control. New Phytologist. v.193, n.1, p.30-50, 2012.

SANDOVAL, M. et al. Anti-inflammatory and antioxidant activities of cat's claw (Uncaria tomentosa and Uncaria guianensis) are independent of their alkaloid content. Phytomedicine. v.9, n.4, p.325-327, 2002.

SAS. SAS/IML® 9.1: User's Guide. Cary, NC: SAS Institute Inc., 2004. 1037p.

SCHEFFER, M.C. Fisiologia de produção de espécies medicinais, condimentares e aromáticas. In: WACHOWICZ, C.M.; CARVALHO, R.I.N. de. Fisiologia vegetal: produção e pós-colheita. Curitiba: Champagnat, 2002. p.225-248.

SILVA, B.M. da S. et al. Efeito da luz no crescimento de mudas Hymeneae parvifolia HUBER. Revista Árvore. v.31, n.6, p.1019-1026, 2007.

SOUZA, A.L. de; CIMERMAN, S. Uncaria tomentosa (Cat's claw): uma potencial estratégia terapêutica para herpes labial. Revista Panamericana de Infectologia. v.12, n.2, p.51-57, 2010.

TAIZ, L.; ZEIGER, E. Fisiologia vegetal. Tradução de E.R. Santarém et al. 3.ed. Porto Alegre: Artmed, 2004. 720p.

TORREJON, G.D. Uña de gato y produccion sustenible. Lima: Universidad Nacional Agraria la Molina, 1997. 137p.

WILLIAMS, J.E. Review of antiviral and immunomodulating properties of plants of the peruvian rainforest with a particular emphasis on Uña de gato 
and Sangre de grado. Alternative Medicine Review. v.6, n.6, p.567-579, 2001.

ZEVALLOS, P.P.; LOMBARDI, I.; BERNAL, Y. Agrotecnología para el cultivo de la uña de gato o bejuco de agua: Fundamentos de agrotecnología para el cultivo de plantas medicinais Iberoamericanas. Santafé de Bogotá: Convenio Andrés Bello/Ciencia y Tecnología para el Desarrollo. 2000. 90p. 